\title{
Texture Evolution in Aluminum Sheet Subjected to Friction Roll Surface Processing and Subsequent Annealing
}

\author{
Yoshimasa Takayama ${ }^{1}$, Ryuichi Hamano ${ }^{1, *}$, Takuya Arakawa ${ }^{1, *}$, \\ Kenta Nonaka ${ }^{1, *}$, Hideo Watanabe ${ }^{1}$ and Hirofumi Inoue ${ }^{2}$ \\ ${ }^{1}$ Department of Mechanical and Intelligent Engineering, Graduate School of Engineering, \\ Utsunomiya University, Utsunomiya 321-8585, Japan \\ ${ }^{2}$ Department of Materials Science, Graduate School of Engineering, \\ Osaka Prefecture University, Sakai 599-8531, Japan
}

Textural evolution in commercial purity aluminum sheet subjected to friction roll surface processing (FRSP) by six combinations of plane/ direction and subsequent annealing has been investigated. The characteristic microstructure consisting of fine- and coarse-grained layers in order from the processed surface are formed in the FRSPed and annealed specimens. The shear texture component E $\{111\}\langle 110\rangle$ mainly evolves in the specimen subjected to FRSP and annealing, the fraction of which depends on FRSP plane and direction.

[doi:10.2320/matertrans.L-M2014847]

(Received July 30, 2014; Accepted December 2, 2014; Published February 25, 2015)

Keywords: severe plastic deformation, friction roll surface processing, preferred orientation, aluminum, recrystallization, electron backscatter diffraction (EBSD)

\section{Introduction}

Severe plastic deformation (SPD) has attracted great interests owing to both formation of extremely fine microstructure and improvement of related properties. Numerous studies have been performed to produce the ultrafine grains and make clear their formation mechanism in various SPD processes such as equal channel angular pressing (ECAP), ${ }^{1)}$ accumulative roll bonding $(\mathrm{ARB})^{2)}$ and high pressure torsion (HPT) ${ }^{3)}$ The crystallographic textures often appeared in the SPDed materials, because extremely large strain should be accompanied with necessary directional priority in slip deformation. The texture evolution during ECAP by only the two shear systems $\{111\}\langle 110\rangle$ and $\{001\}\langle 110\rangle$ ( $\{$ shear plane $\}\langle$ shear direction $\rangle$ ) in an $\mathrm{Al}-\mathrm{Zn}-\mathrm{Mg}-\mathrm{Cu}$ alloy having a strong initial texture was reported. ${ }^{4}$ To an aluminum single crystal ECAP was applied with consistence of theoretical shear plane and direction to crystal slip system, ${ }^{5)}$ and moreover, a crystal plasticity finite element method model showed the textural change with the lattice rotation around the transverse axis of ECAP angle. ${ }^{6}$ For ARB processed aluminum the different local textures corresponding to the different microstructural regions were observed ${ }^{7)}$ and evolution of the textures with strong gradients was investigated in detail with experimental observations and numerical simulations. ${ }^{8)}$ However, attempts to the possibility of texture control by the SPD processes have been limited. On the other hand, it is well known that some of materials properties, such as corrosion, formability and wear, are strongly related to the surface microstructure and texture.

We have proposed a friction roll surface processing (FRSP) as a SPD process for the surface of the sheet materials in order to control microstructure and texture. ${ }^{9,10)}$ As a result of application of FRSP to a commercial purity titanium sheet, ${ }^{9)}$ a large plastic strain was imposed in the

*Graduate Student, Utsunomiya University surface layer and caused grain refinement up to about 100 $\mathrm{nm}$. Characteristic shear textures were formed in the surface layer during FRSP and subsequent annealing, which was strongly related to the processing direction. ${ }^{9,10)}$ It should be noted that the shear texture formed in the FRSPed specimen remained preferential after annealing. Sakai et al. ${ }^{11)}$ already pointed out that the shear texture developed by the shear rolling had a broad one spreading around the typical shear components after annealing. It is, therefore, suggested that the shear texture formed by shear deformation tends to remain after annealing. Shear deformation and subsequent annealing could be a useful way for textural control.

The purpose of the present study is to apply FRSP and subsequent annealing to commercial purity aluminum and investigate texture evolution in specimens subjected to FRSPs with six combinations of plane/direction. Further, the textural evolution is discussed in comparison with that in asymmetric rolling and dependence of FRSP plane and direction.

\section{Experimental Procedure}

\subsection{Material}

Commercial purity aluminum sheet (1050) $1 \mathrm{~mm}$ thick was received as a starting material. It was produced as one of common samples in the Branch Research Committee on Texture, The Japan Institute of Light Metals by a process of casting, hot rolling, cold rolling with a reduction of $90 \%$ and annealing at $623 \mathrm{~K}$ for $3.6 \mathrm{ks}$. Composition of the material used is listed in Table 1.

\subsection{Friction roll surface processing (FRSP)}

Rotational direction of roll, feeding direction of sample and FRSP direction are illustrated in Fig. 1. A fixed roll with a dimension of $\phi 70 \times 5 \mathrm{~mm}$, which was made of tool steel SK3, was rotated at $240 \mathrm{rpm}$. The indentation, defined as the depth at which the rotating roll was pressed down into the 
Table 1 Composition of commercial purity aluminum (1050) used.

\begin{tabular}{cccccccccc}
\hline Material & $\mathrm{Si}$ & $\mathrm{Fe}$ & $\mathrm{Cu}$ & $\mathrm{Mn}$ & $\mathrm{Mg}$ & $\mathrm{Cr}$ & $\mathrm{Zn}$ & $\mathrm{Ti}$ & $\mathrm{Al}$ \\
\hline 1050 & 0.09 & 0.24 & $<0.01$ & $<0.01$ & $<0.01$ & $<0.01$ & $<0.01$ & 0.01 & Bal. \\
\hline
\end{tabular}

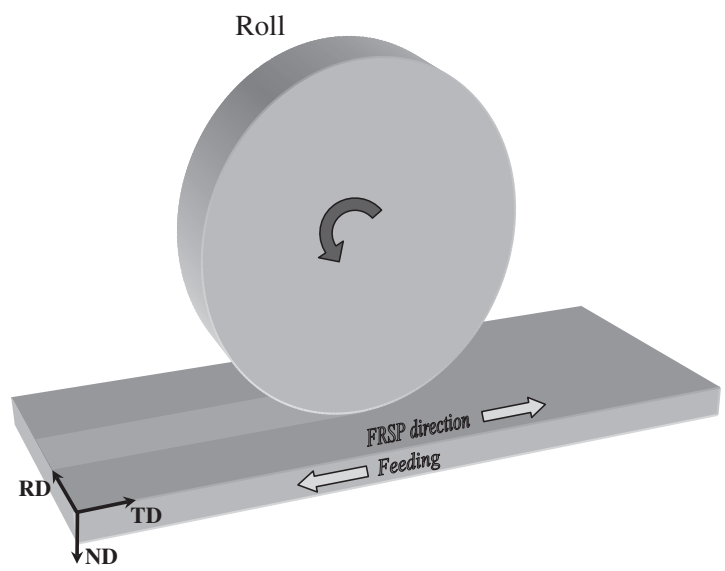

Fig. 1 Schematic illustration of Friction Roll Surface Processing (FRSP) Rotating roll is fed on ND plane in feeding direction, which is parallel to TD (the width direction of rolled sheet sample) in the present figure. This processing is called ND/TD FRSP.

specimen, was selected as $0.1 \mathrm{~mm}$. The feeding speed of specimen was set as $0.3 \mathrm{~mm} / \mathrm{s}$. FRSP was performed as described in our previous studies: ${ }^{9,10)}$ first, the interface where the roll and the specimen just touched was located, and this was regarded as the reference plane at which the indentation was zero. Then, the roll was placed to the given indentation without contacting with the specimen. After rotating the roll, the specimen was moved forward until the entire surface was treated. This procedure resulted in making the working plane lower than the reference plane and led to a great amount of friction. The deformation mode in FRSP is similar to that in asymmetric rolling (ASR). Tangential speed of FRSP roll is faster than feeding speed on the surface layer of the material while a faster tangential speed of rolls in ASR is almost similar to a moving speed of surface material in ASR. After FRSP, the specimens were annealed at $573 \mathrm{~K}$, $623 \mathrm{~K}$ or $673 \mathrm{~K}$ for $3.6 \mathrm{ks}(1 \mathrm{~h})$ in $\mathrm{Ar}$ gas and air cooled to study the texture evolution during annealing.

Here the plane and the direction of the specimen subjected to FRSP are expressed as plane/direction sited before "FRSP", where the rolling, transverse and normal directions (RD, TD and ND, respectively) are used as the specimen axes. For example, ND/TD FRSP (See Fig. 1) refers to the processing in which FRSP was performed on ND plane (the plane perpendicular to ND) of the specimen along the direction parallel to TD.

\subsection{Microstructural analysis and mechanical measure- ment}

Crystallographic textures of annealed specimens were evaluated using a scanning electron microscope/electron back scatter diffraction pattern technique (SEM/EBSD; HITACHI S-3500H, TSL Orientation Image Microscopy system) after electropolishing. The electropolishing was

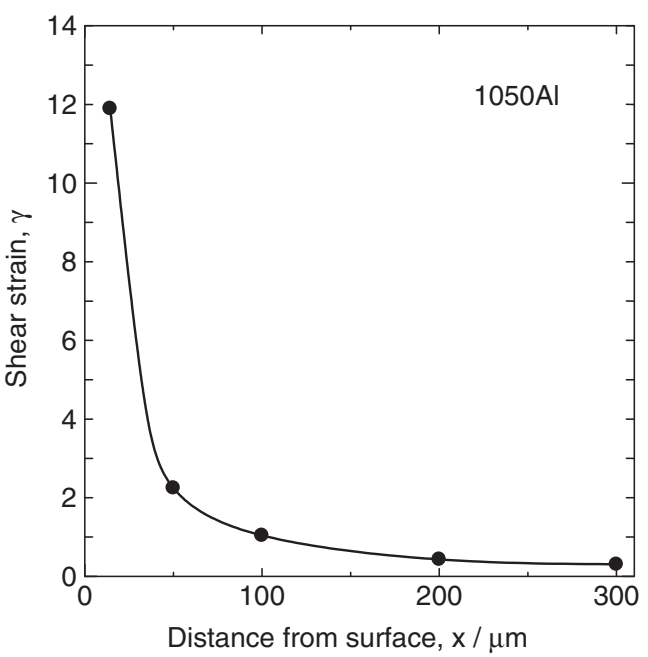

Fig. 2 Shear strain imposed by FRSP as a function of distance from the processed surface in 1050 aluminum.

carried out at $283 \mathrm{~K}$ and $8 \mathrm{~V}$ for $480 \mathrm{~s}$ in a solution containing perchloric acid and ethanol with a ratio of $1 / 8$. The scan areas were chosen on the cross sections of the specimen perpendicular to FRSP direction. Microstructure and texture evolution through the thickness of specimen was investigated from the processed surface to center of the specimen, the area was $400 \mu \mathrm{m} \times 400 \mu \mathrm{m}$ and the step size was $3 \mu \mathrm{m}$.

Global textures were measured as $\{100\}$ and $\{111\}$ incomplete pole figures using $\mathrm{CuK} \alpha_{1}$ radiation by $\mathrm{X}$-ray diffraction (XRD) in as received, ND/TD FRSPed and subsequently annealed specimens to reveal a difference in texture before and after FRSP and annealing.

Shear strain measurement was carried out by the embedded-pin method. ${ }^{12)}$ Micro Vickers hardness was measured on the plane perpendicular to FRSP direction of the specimens with a load of $0.245 \mathrm{~N}$ and a holding time of $30 \mathrm{~s}$.

\section{Results}

\subsection{Shear strain distribution}

In order to confirm amount of shear strain imposed on the surface of the aluminum sheet, the shear strain distribution through the thickness of the ND/RD FRSPed specimen with an indentation of $0.1 \mathrm{~mm}$ and a tool rotation speed of $240 \mathrm{rpm}$ was measured. Figure 2 shows strain gradient along the thickness after FRSP. Shear strain of 11.9 was imposed at a site of $14 \mu \mathrm{m}$ beneath the surface. The strain falls off drastically to 2.25 when the depth is $50 \mu \mathrm{m}$. In comparison to the previous result of commercial purity titanium, ${ }^{10,13)}$ the concentration of strain to the surface in the present aluminum is observed. It is likely due to a difference in ductility between the two specimens.

\subsection{Hardness distribution}

Vickers hardness along the normal direction of the FRSP plane as a function of the distance from the processed surface of the six FRSPed specimens is displayed in Fig. 3. The hardness and its gradient obviously depend on the FRSP plane and direction. As expected, the maximum hardness 
appeared near the surface for all of the FRSP conditions. The hardness lowered as the distance from the FRSP surface increased. The hardness for the specimens subjected to FRSP on ND (or RD-TD) plane tends to be highest. FRSP on RD (or TD-ND) plane likely lead to relatively high hardness also.

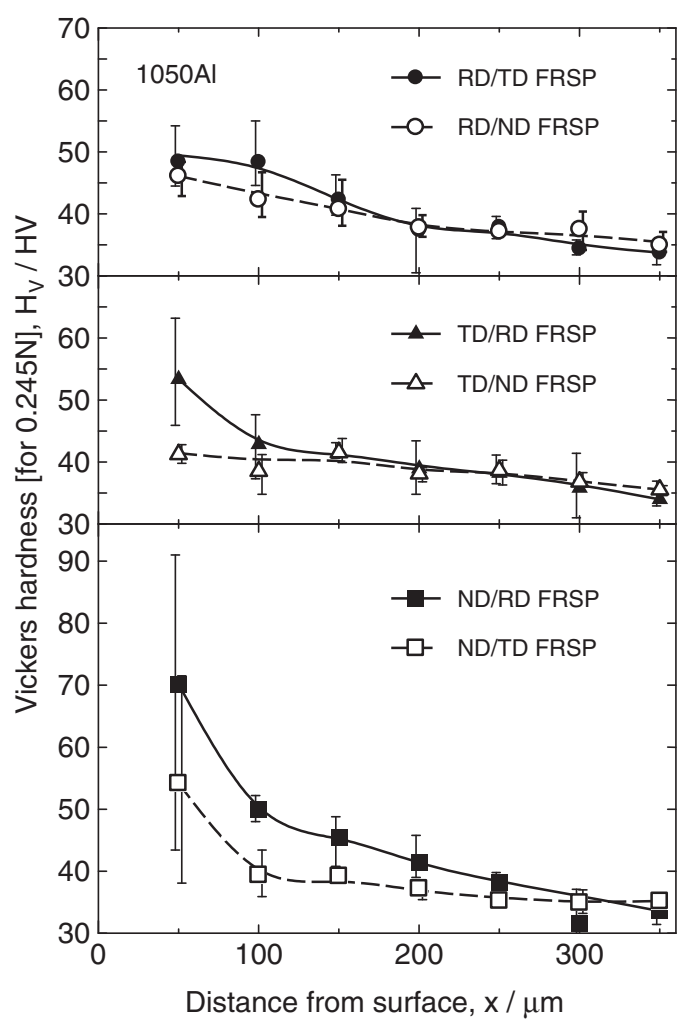

Fig. 3 Vickers hardness as a function of distance from the processed surface in six kinds of FRSPed specimens.
The specimens subjected to the FRSP along RD, TD and ND in order seem to exhibit the higher maximum hardness near the surface. Further, low hardness gradient is found for RD/ TD, RD/ND and TD/ND FRSP conditions. These hardness features are explained from grain shape or grain boundary density in specimen directions. Because the as-received sheet was annealed after cold rolling with a high reduction of $90 \%$, grain intercept lengths in RD, TD and ND are larger in order. Thus, grain intersect area is the largest on ND plane while the smallest on RD. Generally the shear deformation is easier on the plane with larger grain area. Moreover, the shear deformation occurs easily in direction of large grain intercept. Therefore, the hardness feature is regarded as results of difference in strain hardening for FRSP plane and direction on non equiaxed grains.

\subsection{Texture of processed materials}

The normalized pole figures of as-received, ND/TD FRSPed and subsequently annealed specimens measured by XRD are presented in Fig. 4. As shown in Fig. 4(a), $\{100\}$ and $\{111\}$ pole figures of the as received specimen indicate typical cube texture. The $\{100\}$ pole of ND/TD FRSPed specimen (Fig. 4(b)) shows very weak intensity of $\langle 001\rangle / /$ ND while the $\{111\}$ pole implies $\langle 110\rangle / /$ TD. Then, the main textural component is $\{001\}\langle 110\rangle$ (\{FRSP plane $\}\langle$ FRSP direction $\rangle)$. The central intensity of the $\{111\}$ pole extended in $\mathrm{RD}$ likely means formation of the main component rotated about TD axis. After the annealing (Fig. 4(c)), $\{001\}\langle 110\rangle$ orientation is somewhat sharpened though the characteristically rotated spread of the main component remains after annealing.

These results probably show the texture formed mainly in the surface layer with thickness of $10 \mu \mathrm{m}$ order as they were obtained by X-ray diffraction with penetration depth ranging (a) As-received

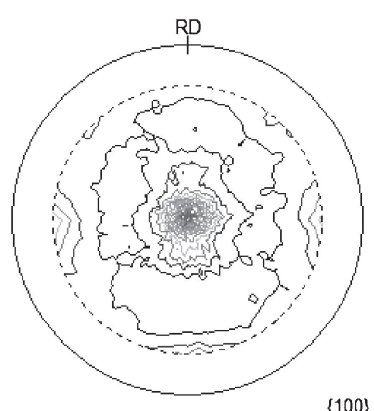

$\{100\}$

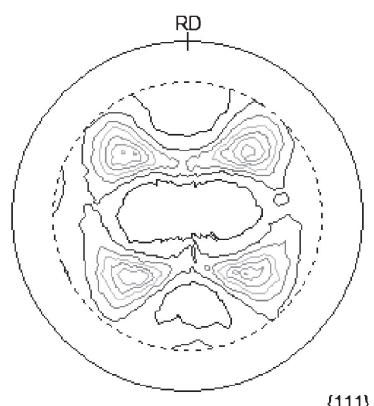

(b) FRSPed

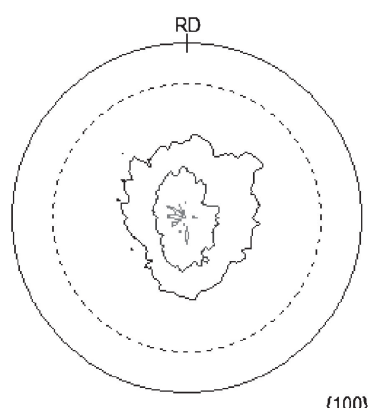

$\{100\}$

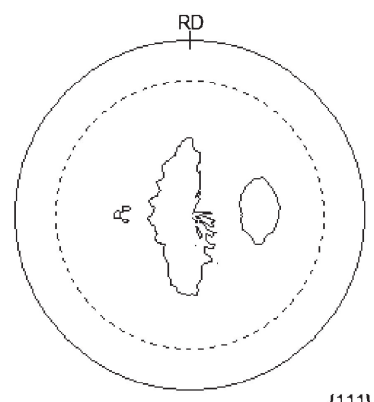

(c) Annealed

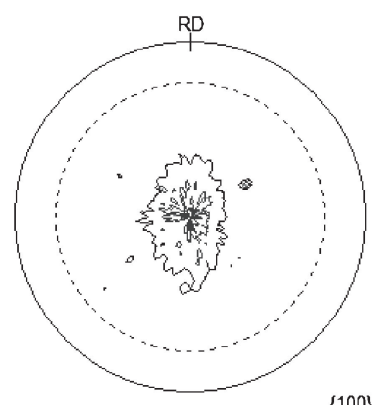

$\{100\}$

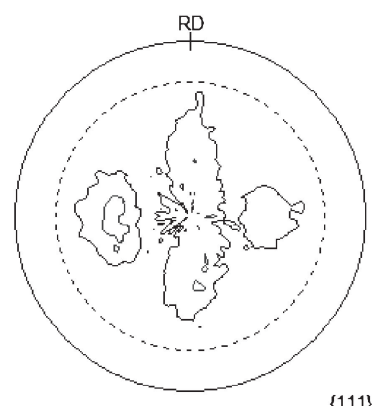

$\{111\}$

Fig. 4 Pole figures showing difference in texture before and after FRSP and subsequent annealing in 1050 aluminum. (a) As received, (b) ND/RD FRSPed and (c) Annealed samples. Contour levels of pole figures in (a): 0.5, 1.0, 1.5, 2.0, 2.5, 3.0, 3.5, 4.0, 4.5, 5.0, 5.5, 6.0, 6.5, 7.0; Contour levels in (b): 0.8, 1.0, 1.2; Contour levels in (c): 0.8, 1.0, 1.2, 1.4. 
from 0.01 to $0.1 \mathrm{~mm}$. The texture after annealing is also mentioned below based on EBSD analysis on cross-section.

\subsection{Microstructure after annealing}

First, the orientation map at the center in ND on TD plane of as-received sample is shown in Fig. 5. Color of all orientation maps in the present study refer to crystallographic direction in the sample direction perpendicular to the map, which is TD in this figure. The sample has a grain structure with grain size ranging from 20 to $50 \mu \mathrm{m}$, which is elongated slightly in RD. Since the sample had a typical cube texture, lots of red colored grains indicating $\mathrm{TD} / /\langle 010\rangle$.

Figure 6 shows orientation maps representing microstructures in the vicinity of the FRSPed surface of the 1050 aluminum specimens which were subjected to four kinds of

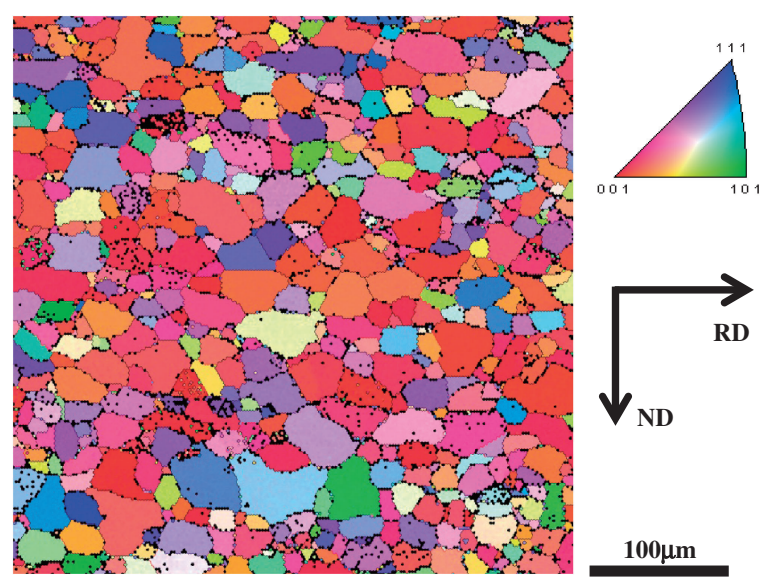

Fig. 5 Orientation map on TD (or RD-ND) plane of as-received sample. Color in this map refers to crystallographic direction in the sample direction perpendicular to the analyzed plane.
FRSP and annealing (which is sometimes abbreviated as FRSP/A below) processes. The analyzed plane is perpendicular to FRSP direction, and the left side edge is FRSP plane in the figures while color designates crystallographic direction in normal one of FRSP plane. The orientation map on TD plane of the specimen subjected to RD/TD FRSP and subsequent annealing at $573 \mathrm{~K}$ is shown with a horizontal axis parallel to RD in Fig. 6(a). Characteristic microstructure consisting of fine grained (FG), coarse grained (CG) and remaining (RE) layers in order from the processed surface of the specimen is observed for all of specimens shown. The FG and CG layers are displayed in the attached small figures (magnification is $1 / 2$ to the main figure) in right-hand side, respectively. The FG layer is found to be composed of grains smaller than about $30 \mu \mathrm{m}$. Some grains elongated in slanting direction are supposed to relate to tilt of specimen edge in EBSD analysis. In contrast, coarse grains of size more than $80 \mu \mathrm{m}$ are found in the CG layer. Shapes of coarse grains may depend on the microstructure before FRSP. The elongated coarse grains tend to result from the grains elongated by rolling before FRSP (Figs. 6(a) and (b)). It should be noted that characteristic wavy grain boundaries (arrows show typical ones in the figure), which imply to have relatively low energy and to be accompanied by low angle grain boundaries (or subboundaries) inside the grain, are often observed in the CG layer, especially in the specimens subjected to FRSP with the processed direction parallel to TD, and besides at higher annealing temperature (Fig. 6(d)). As shown in Fig. 2, FRSP imposed shear strain to the distance of about $300 \mu \mathrm{m}$ from the processed surface. Thus, the deep inside area with little strain, namely the RE layer, was almost unchanged after annealing. Some RE layers exhibit orientation gradation inside grains of the specimens annealed at $573 \mathrm{~K}$ (Fig. 6(a)). It may be attributed to an
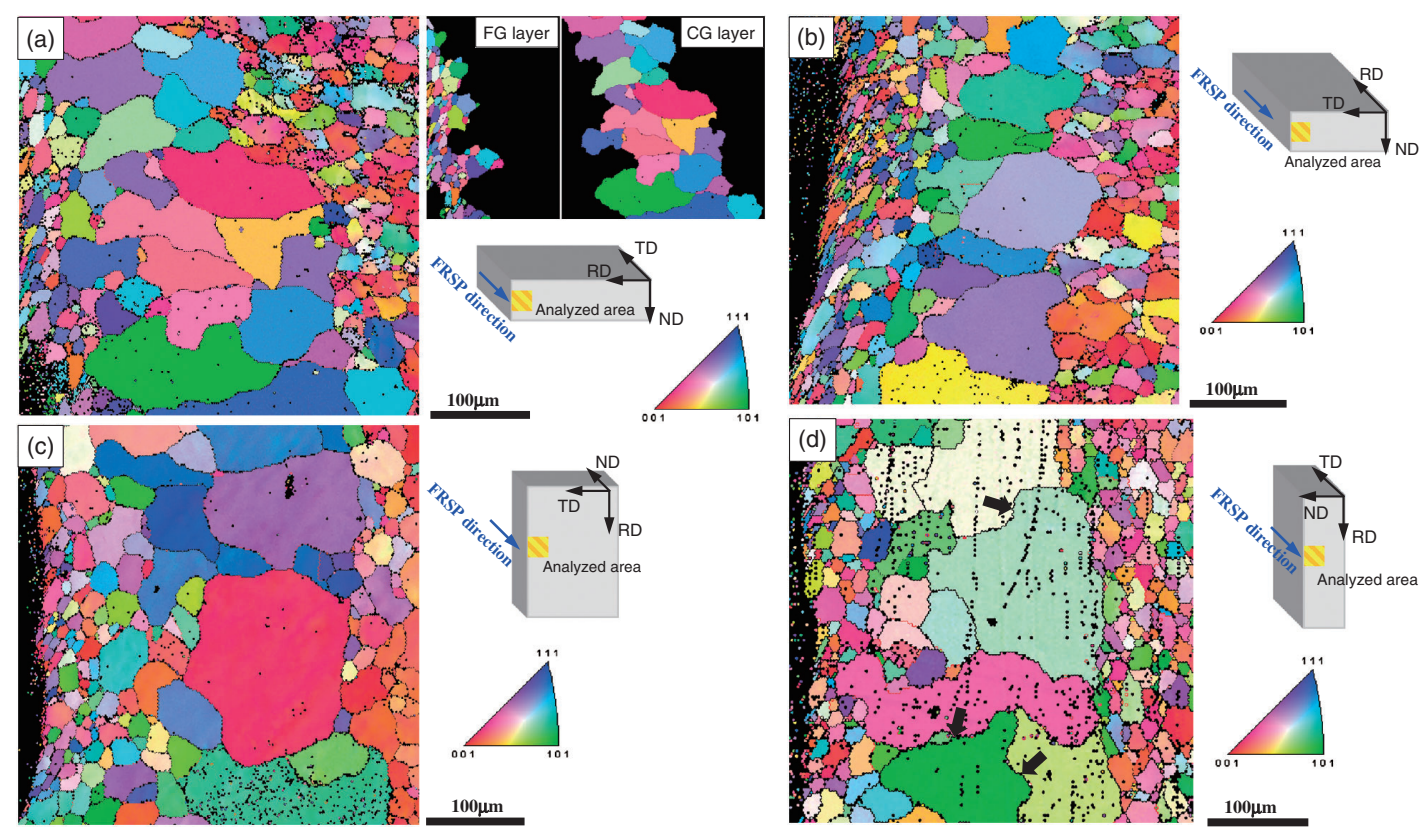

Fig. 6 Orientation maps showing microstructure which consists of fine- and coarse-grained layers near the surface of the specimens subjected to FRSP and subsequent annealing; color designates crystallographic direction in normal direction of FRSP plane: (a) RD/TD FRSP and annealing at $573 \mathrm{~K}$; Attached figures in right-hand side refer to fine grained (FG) and coarse grained layers, respectively, (b) $\mathrm{TD} / \mathrm{RD}$ at $573 \mathrm{~K}$, (c) TD/ND at $673 \mathrm{~K}$ and (d) ND/TD at $623 \mathrm{~K}$; Arrows show typical wavy boundaries in the coarse grained layer. 
increase in intragranular misorientation during recovery. ${ }^{14)}$ Annealing at higher temperature leads to larger grains and wider thickness in both the FG and CG layers (Fig. 6(c)).

Formation of the FG and CG layers can be understood as more nuclei of recrystallization can lead more recrystallized grains. In fact, fine recrystallized grains were formed from many nuclei generated by larger strain near the FRSPed surface while coarse recrystallized grains from fewer nuclei generated in the inside layer subjected to smaller strain.

All of the FRSPed and annealed specimens exhibited similar microstructures of the three layers. However, fractions of FG and CG layers are not independent of kinds of specimens, that is, FRSP parameters. Figure 7 displays fractions of the layers on six kinds of specimens subjected to different FRSPs and subsequent annealing at different temperatures.

As shown in the figure, the fraction of FG layer in specimens FRSPed on RD and ND planes is small while that on TD is relatively large in annealing at $573 \mathrm{~K}$. Similar tendency is also found in the specimens annealed at $623 \mathrm{~K}$. For annealing at $673 \mathrm{~K}$, the FG fraction of ND/RD FRSPed specimen is the largest, but clear dependence on FRSP parameters was not found. The fraction of CG layers is almost correspondent to that of the FG layers for annealing at three temperatures. The fraction of CG layers increases with that of FG layers. This is attributed to a difference in stored strain for each FRSP condition. Amount and concentration of the stored strain by FRSP is likely related to the plane and direction subjected to FRSP as the hardness feature exhibited above (Fig. 3). Smaller fraction implies severer or sharper concentration of strain to the vicinity of the FRSPed surface. It is clear that FRSP on ND led to severer deformation to the surface, as shown as the higher hardness. On the other hand, FRSP on RD must be difficult in deformation owing to the smallest grain intersect area. The deformation was probably concentrated sharply to the surface though marked rise in hardness was not detected. It can be, therefore, understood that both of FRSPs on RD and ND planes produce concentrated strain to the narrow FG layers after annealing.

After the annealing at higher temperatures, the wider FG layers with growth of grain itself were formed. The wider CG layers were also extended to the right hand side of the analyzed area of EBSD. Then, sum of fractions of FG and CG layers reached $100 \%$ in some of specimens annealed at $623 \mathrm{~K}$ and $673 \mathrm{~K}$.

\subsection{Texture evolution during annealing}

As mentioned in the first chapter, the typical shear texture was observed in the FRSPed and annealed titanium. ${ }^{9,10)}$ Moreover, similarity and difference of FRSP with asymmetric rolling are interesting for us in formation of preferred orientation. Several studies on asymmetric rolling (ASR) of pure aluminum were conducted to examine preferred orientations. ${ }^{15-17)}$ They reported that the three typical components of the shear texture, $\mathrm{H}\{001\}\langle 110\rangle$, E $\{111\}\langle 110\rangle$, and $F\{111\}\langle 112\rangle$ were formed by ASR in aluminum and its alloys. Thus, for comparison fractions of the three components were also investigated in the present study. An orientation $\{\mathrm{hkl}\}\langle\mathrm{uvw}\rangle$ means $\{$ FRSP plane $\}\langle$ FRSP direction〉 for FRSPed specimens below.

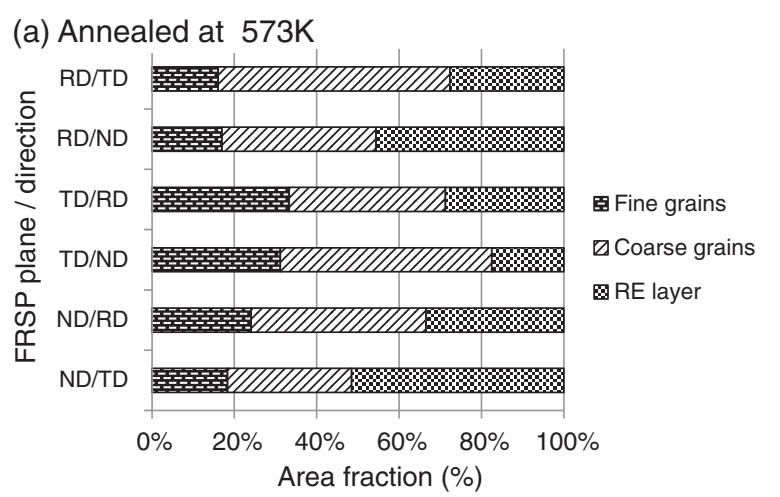

(b) Annealed at $623 \mathrm{~K}$

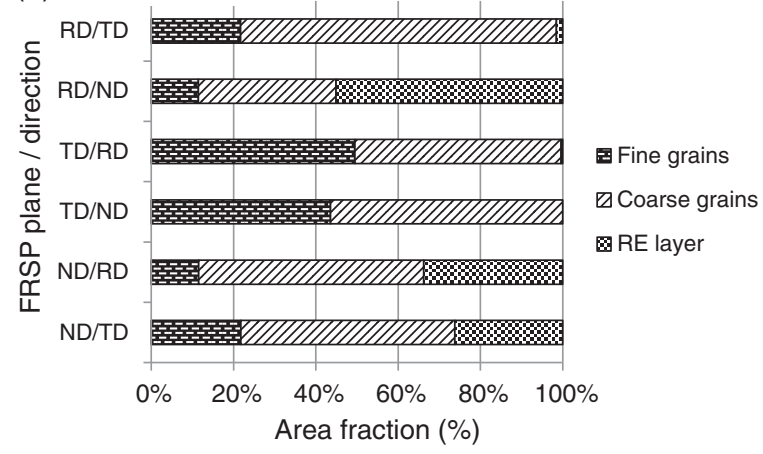

(c) Annealed at $673 \mathrm{~K}$

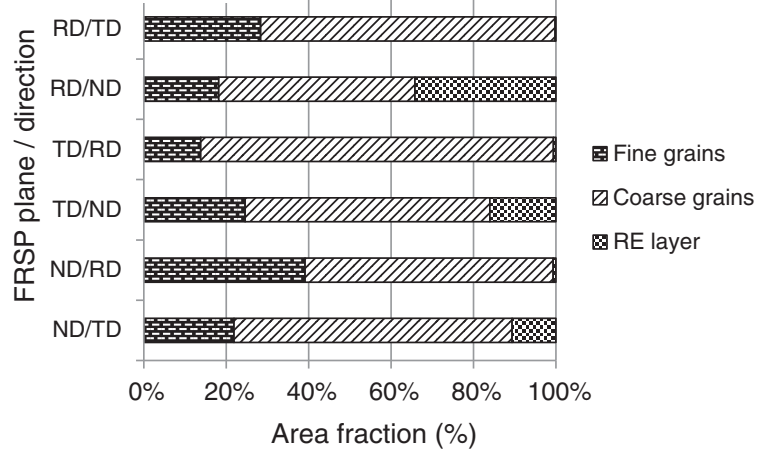

Fig. 7 Fractions of FG and CG Layers in analyzed area of FRSPed and Annealed samples: annealing temperature (a) $573 \mathrm{~K}$, (b) $623 \mathrm{~K}$ and (c) $673 \mathrm{~K}$.

In order to obtain the fundamental data on the shear texture, fractions of fiber textures FRSP_nd// $\langle 100\rangle$, FRSP_nd// $/ 111\rangle$ and FRSP_d// $\langle 110\rangle$, where FRSP_nd is normal direction of FRSP plane and FRSP_d is FRSP direction.

Figure 8 displays fractions of FRSP_nd $/ /\langle 100\rangle$ for the FG and CG layers formed in the six kinds of FRSPed specimens annealed at three temperatures, with as-received specimen. Fractions are expressed as ones of the whole analyzed area. The as-received one was analyzed on the cross-section corresponding to FRSP plane and direction. For example, $\mathrm{RD} / \mathrm{TD}$ in the as-received specimen means the fraction of $\mathrm{RD} / /\langle 100\rangle$ analyzed for the area sited in the center of $\mathrm{ND}$ on TD plane. As shown in the figure, fraction of $\mathrm{RD} / /\langle 100\rangle$ is relatively high both on TD and ND planes (RD/TD and $\mathrm{RD} /$ $\mathrm{ND}$ of as-received). On the other hand, fraction of $\mathrm{ND} / /\langle 100\rangle$ is relatively low about $20 \%(\mathrm{RD} / \mathrm{TD}$ and $\mathrm{RD} / \mathrm{ND})$. Fraction of $\mathrm{TD} / /\langle 100\rangle$ shows a difference between analyzed areas on different cross-sections (TD/RD and TD/ND). After FRSP and annealing the fractions of FRSP_nd $/ /\langle 100\rangle$ decrease in all 
(a) As-received

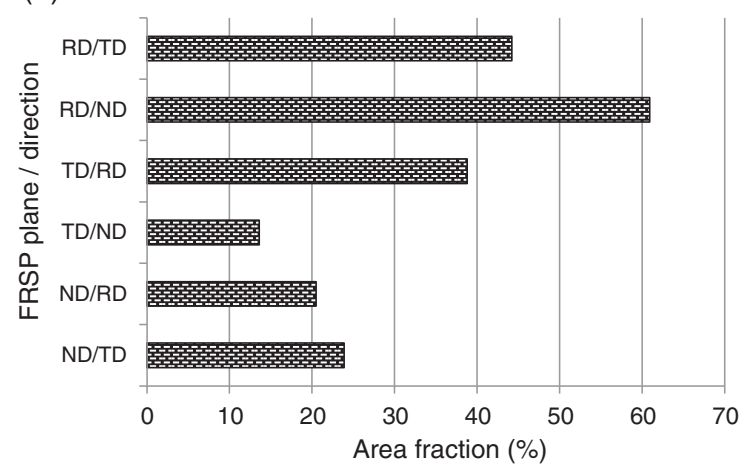

(c) Annealed at $623 \mathrm{~K}$

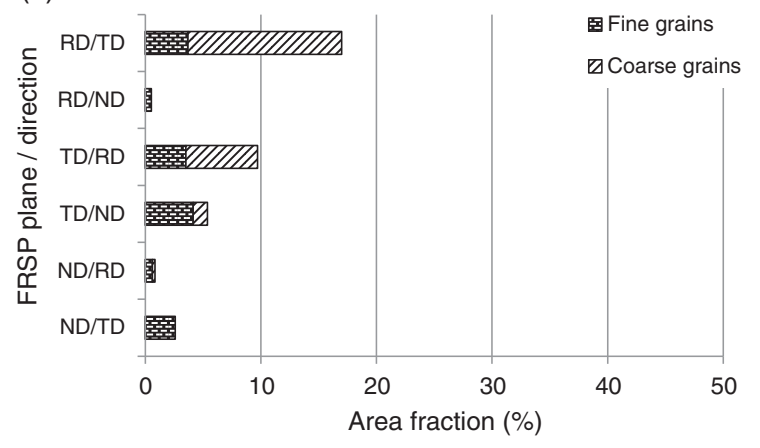

(b) Annealed at $573 \mathrm{~K}$

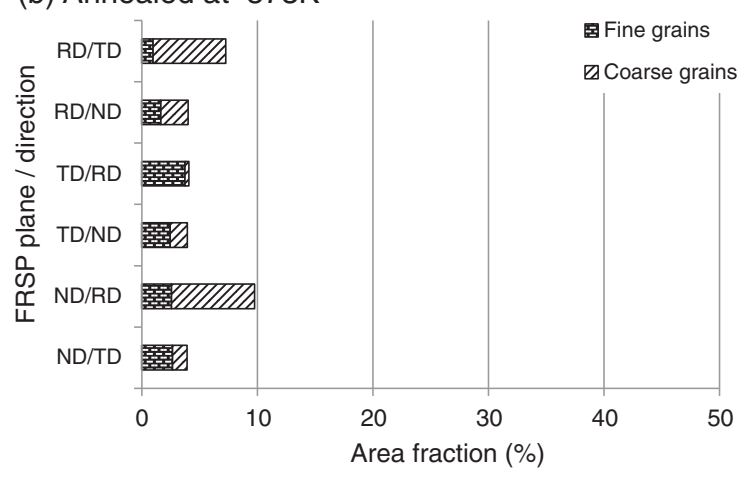

(d) Annealed at $673 \mathrm{~K}$

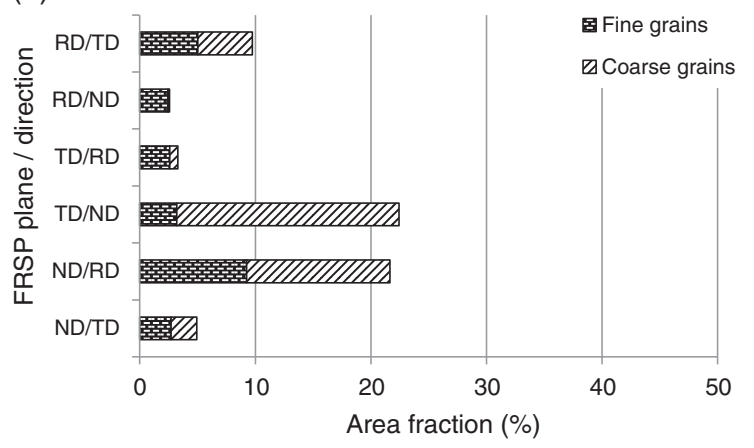

Fig. 8 Fractions of FRSP_nd// $\langle 100\rangle$ fiber texture in fine- and coarse-grained layers of FRSPed specimens after annealing at $573 \mathrm{~K}$, $623 \mathrm{~K}$ and $673 \mathrm{~K}$.

of FRSP/A conditions on the whole. In the FG layer the fractions of FRSP_nd $/ /\langle 100\rangle$ tend to increase with annealing at the higher temperature whereas their values are limited below $10 \%$. Some high fractions of the FG and CG layers are also observed in the specimens annealed at $673 \mathrm{~K}$ after TD/ ND and ND/RD FRSPs.

Fractions of FRSP_nd $/ /\langle 111\rangle$ fiber texture in as-received and FRSP/Aed specimens are displayed in Fig. 9. The fractions of the as-received specimen are just less than $8 \%$. FRSP and annealing produced FRSP_nd $/ /\langle 111\rangle$ fiber texture both in FG and CG layers. FRSP on RD and ND planes seems to lead high fraction about $4 \%$ in FG layers of the specimen annealed at $573 \mathrm{~K}$ except for ND/TD FRSP. In CG layers high fractions are found corresponding to those in FG layers. Annealing at higher temperatures often produced significantly high fractions more than $20 \%$ in CG layers while the maximum total fraction in $\mathrm{FG}$ and $\mathrm{CG}$ layers reached $29.7 \%$ for RD/ND FRSP and annealing temperature of $623 \mathrm{~K}$. The total fraction was not extended on the whole by annealing at $673 \mathrm{~K}$. The fraction of ND/TD FRSPed specimen was limited in the three kinds of annealing temperatures especially in CG layers.

Fractions of FRSP_d $/ /\langle 110\rangle$ are also displayed in Fig. 10 in the same way. The fractions of the as-received specimen were comparatively small except for $24.1 \%$ in TD/ND FRSP. The fractions increased markedly with FRSP and annealing as well as that of FRSP_nd $/ /\langle 111\rangle$. After annealing at $573 \mathrm{~K}$ the FRSP_d $/ /\langle 110\rangle$ texture developed more than total fraction of $20 \%$ in FG and CG layers except for RD/ND and ND/TD FRSPs. The maximum total fraction was $38.1 \%$ in the TD/ ND FRSPed specimen. After annealing at higher temper- atures, the total fraction ranged from $5 \%$ to $30 \%$. This will be discussed below.

Figure 11 shows fractions of Cube $\{001\}\langle 100\rangle$ in asreceived and FRSP/Aed specimens. Cube orientation is the main component of the as-received specimen. As shown in the figure, the fraction of Cube orientation almost corresponds to that of the FRSP_nd $/ /\langle 001\rangle$ fiber texture (Fig. 8). It is confirmed that FRSP and the subsequent annealing reduced the fraction of Cube orientation to less than $4 \%$. In the case of TD/ND FRSP in which the fraction of the as-received specimen was lower than $10 \%$, Cube orientation, however, developed to $18.3 \%$ in fraction of $\mathrm{CG}$ layer after annealing at $673 \mathrm{~K}$. During the annealing at the relatively high temperature priority of a preferred orientation tends to lower to competitive ones because difference in nucleation rate between both orientations is reduced. This likely results in development of Cube grain as a competitive orientation.

Figure 12 shows fractions of $H\{001\}\langle 110\rangle$ in as-received and FRSP/Aed specimens. H orientation was detected in the global texture measurement by XRD as a main component of the FRSPed and the subsequently annealed specimens (Fig. 4), whereas the intensities were fairly weak. Fraction of $\mathrm{H}$ orientation in the as-received specimen is very small being less than $5 \%$. After annealing $\mathrm{H}$ orientation is built up slightly in $\mathrm{CG}$ layer at lower temperatures for RD/TD.

Figure 13 shows fractions of $\mathrm{F}\{111\}\langle 112\rangle$ in asreceived and FRSP/Aed specimens. Fraction of F orientation in the as-received specimen is also very small being less than $3 \%$. Compared with $\mathrm{H}$ orientation, fraction of $\mathrm{F}$ orientation after annealing is somewhat large and has a 
(a) As-received

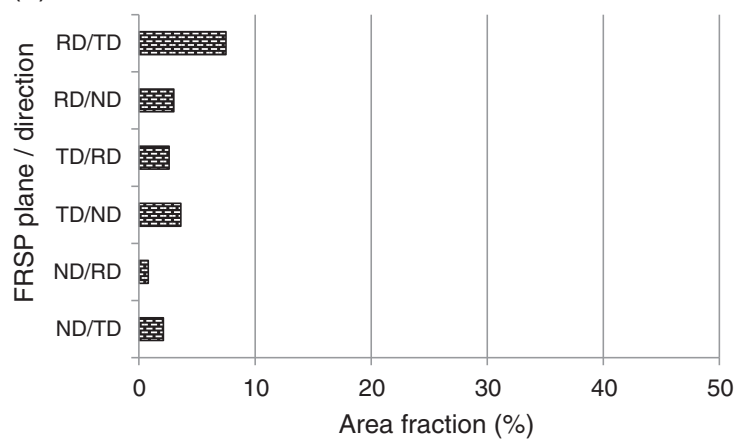

(c) Annealed at $623 \mathrm{~K}$

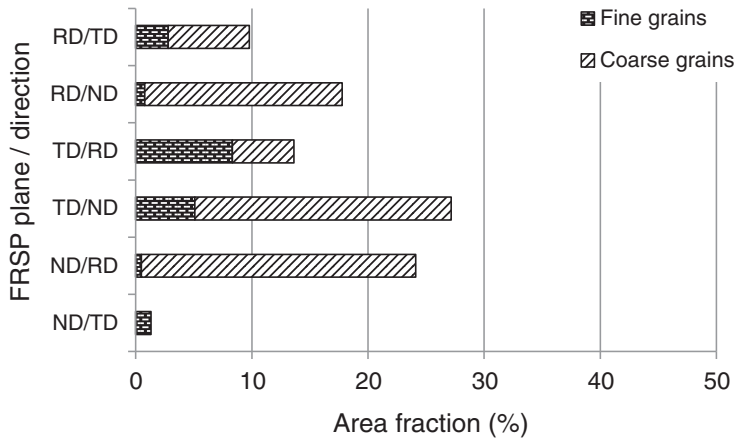

(b) Annealed at $573 \mathrm{~K}$

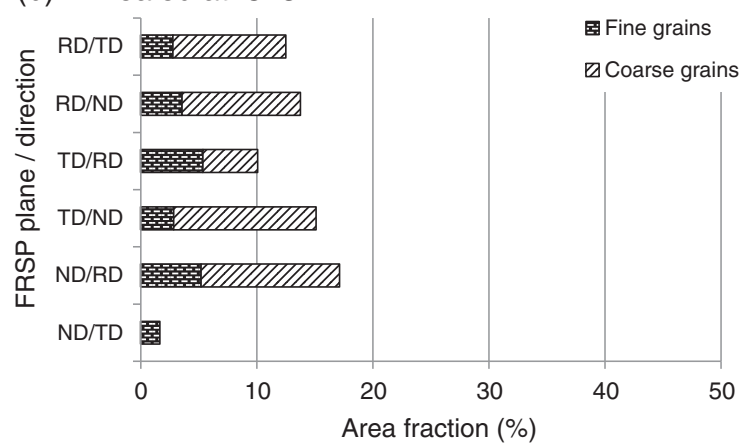

(d) Annealed at $673 \mathrm{~K}$

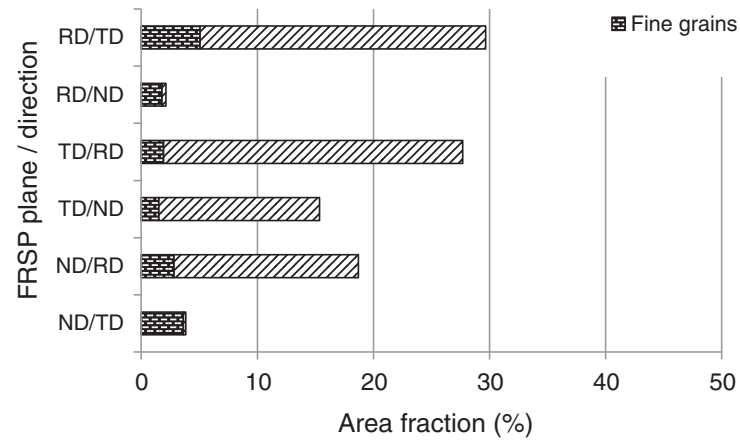

Fig. 9 Fractions of FRSP_nd// $\langle 111\rangle$ fiber texture in fine- and coarse-grained layers of FRSPed specimens after annealing at $573 \mathrm{~K}, 623 \mathrm{~K}$ and $673 \mathrm{~K}$.

(a) As-received

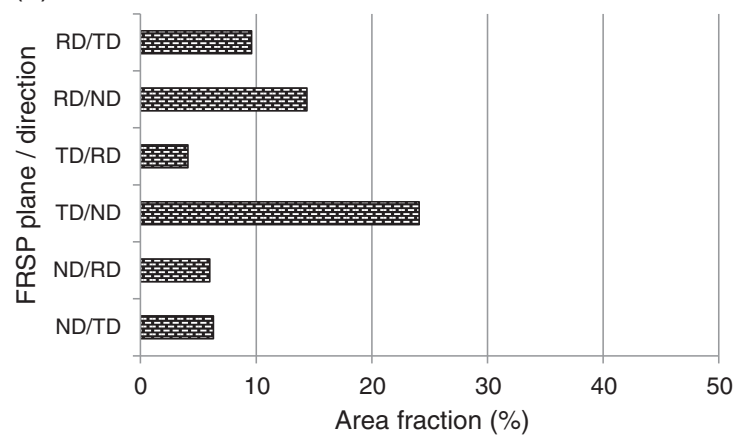

(c) Annealed at $623 \mathrm{~K}$

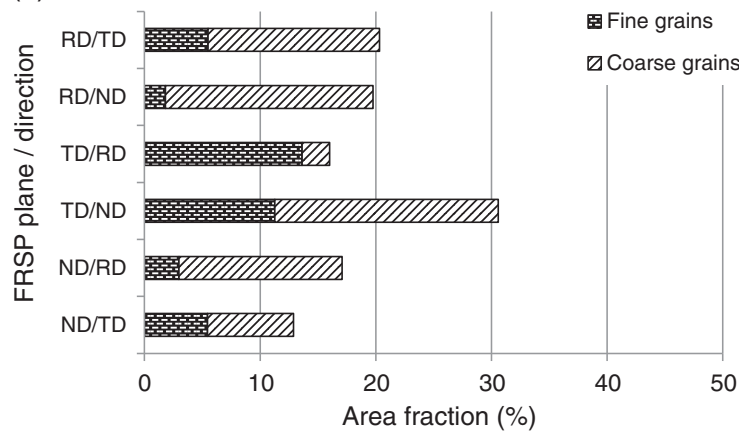

(b) Annealed at $573 \mathrm{~K}$

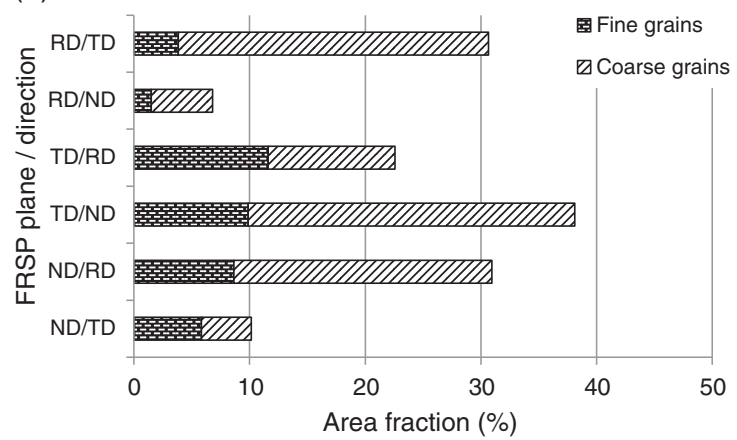

(d) Annealed at $673 \mathrm{~K}$

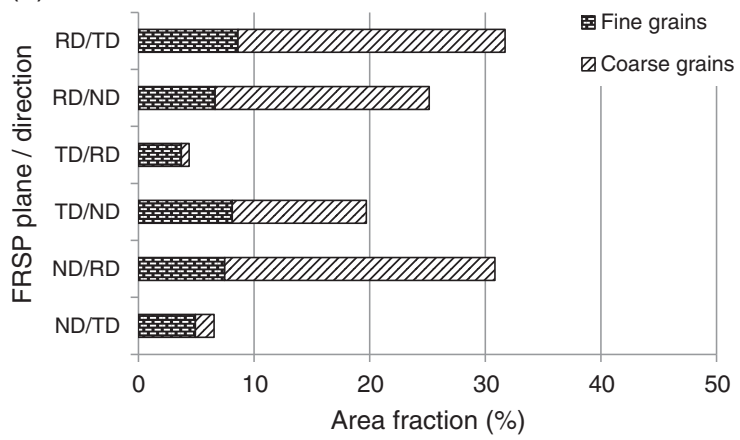

Fig. 10 Fractions of FRSP_d// 1110$\rangle$ fiber texture in fine- and coarse-grained layers of FRSPed specimens after annealing at $573 \mathrm{~K}$, $623 \mathrm{~K}$ and $673 \mathrm{~K}$.

distinct difference between FRSP conditions. In the $573 \mathrm{~K}$ annealed specimens, RD/ND FRSP gave a slightly large fraction of $6.7 \%$ in total of $\mathrm{FG}$ and $\mathrm{CG}$ layers. After annealing at $623 \mathrm{~K}, \mathrm{~F}$ orientation reached $5.1 \%$ and $13.0 \%$ in $\mathrm{TD} / \mathrm{RD}$ and $\mathrm{ND} / \mathrm{RD}$ FRSPed specimens, respectively while the fractions were less than $5.0 \%$ for all specimens annealed at $673 \mathrm{~K}$.

E $\{111\}\langle 110\rangle$ is a typical and well-understandable component of shear texture in fcc metals because FRSP plane and direction are consistent with indices of slip planes 
(a) As-received

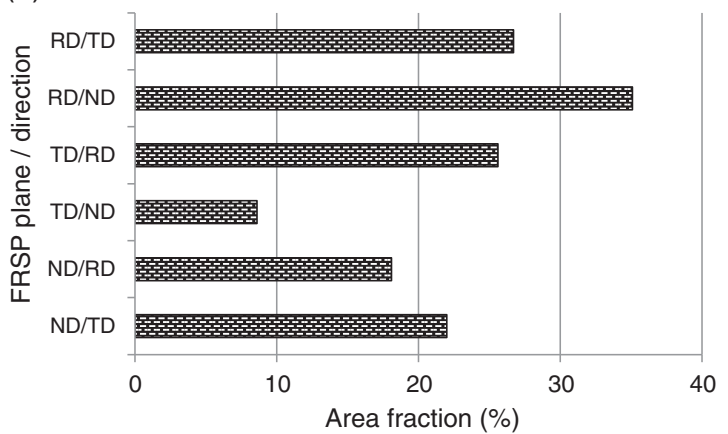

(c) Annealed at $623 \mathrm{~K}$

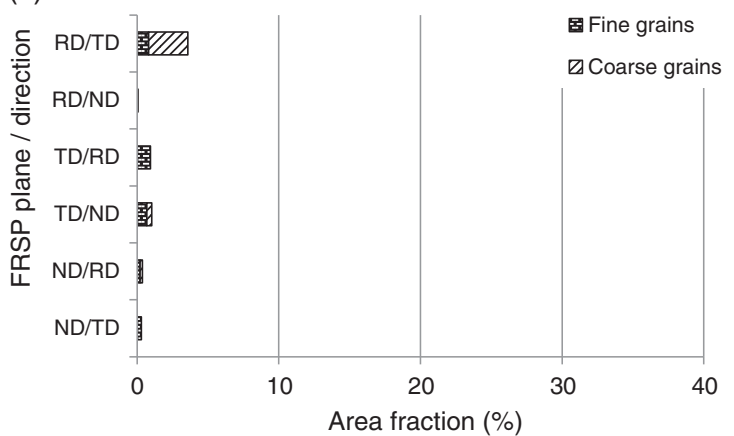

(b) Annealed at $573 \mathrm{~K}$

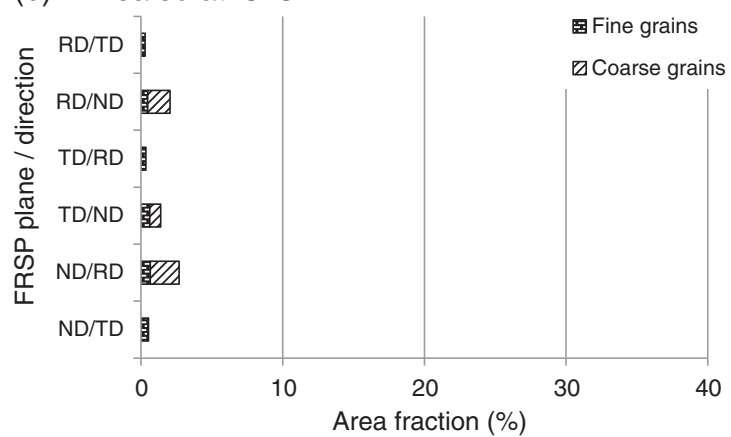

(d) Annealed at $673 \mathrm{~K}$

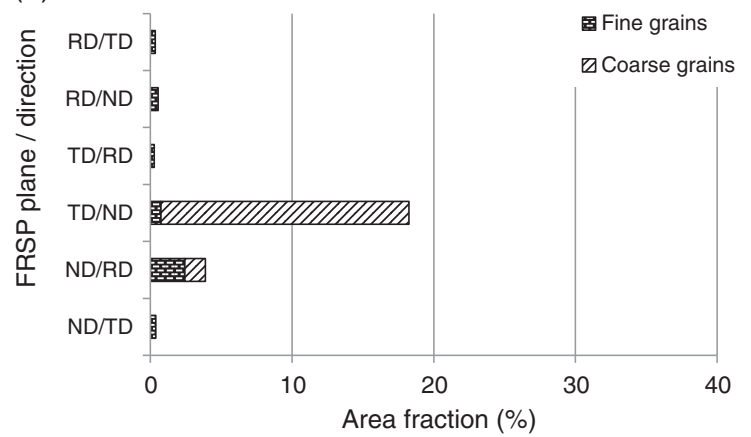

Fig. 11 Fractions of Cube $\{001\}\langle 100\rangle$ orientation in fine- and coarse-grained layers of FRSPed specimens after annealing at $573 \mathrm{~K}$, $623 \mathrm{~K}$ and $673 \mathrm{~K}$.

(a) As-received

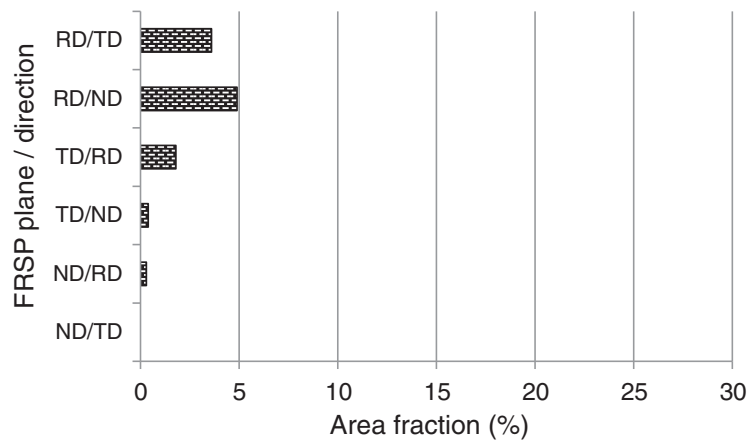

(c) Annealed at $623 \mathrm{~K}$

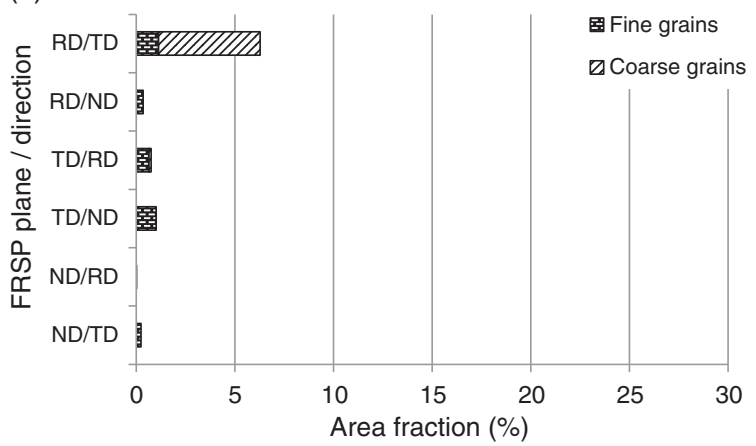

(b) Annealed at $573 \mathrm{~K}$

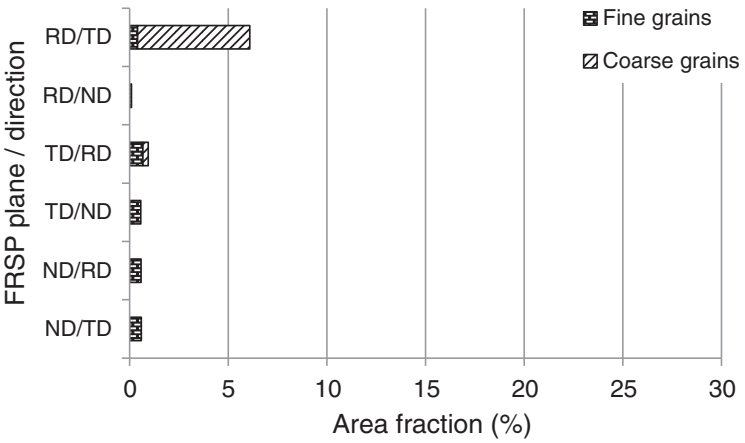

(d) Annealed at $673 \mathrm{~K}$

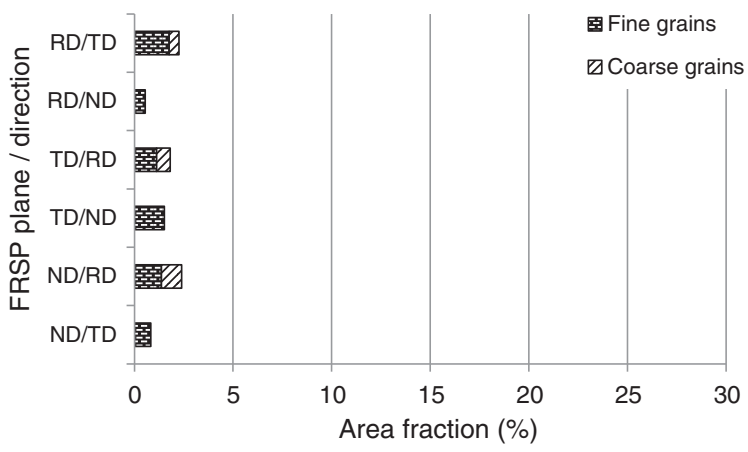

Fig. 12 Fractions of $\mathrm{H}\{001\}\langle 110\rangle$ orientation in fine- and coarse-grained layers of FRSPed specimens after annealing at $573 \mathrm{~K}$, $623 \mathrm{~K}$ and $673 \mathrm{~K}$.

and directions, respectively. Figure 14 exhibits fractions of $\mathrm{E}$ $\{111\}\langle 110\rangle$ in as-received and FRSP/Aed specimens. The asreceived specimen has a small amount of $\mathrm{E}$ orientation less than $3.3 \%$ for all FRSP setting. Generally, E orientation in FG layers developed more with a lower annealing temperature of $573 \mathrm{~K}$. Partial fractions of $\mathrm{E}$ in FG layer were calculated as $5.0 \%$ at $573 \mathrm{~K}$ and $3.7 \%$ at $673 \mathrm{~K}$ in average. In contrast, E orientation in CG layers increase in some FRSP conditions limited, and then, the increments become larger and more limitedly with the higher temperature. The maximum total fraction of $\mathrm{E}$ orientation is obtained as $22.0 \%$ (2.9\% in FG and $19.1 \%$ in CG) for RD/TD FRSP and 
(a) As-received

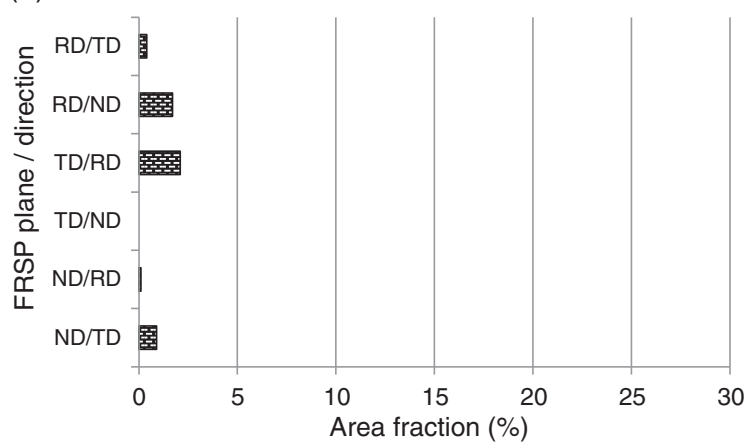

(c) Annealed at $623 \mathrm{~K}$

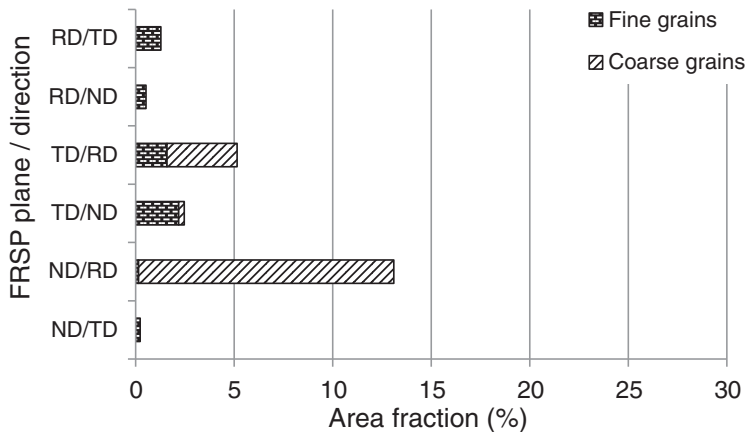

(b) Annealed at $573 \mathrm{~K}$

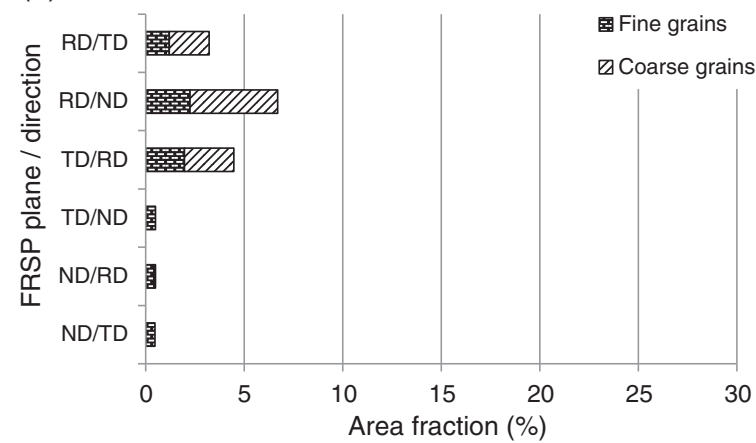

(d) Annealed at $673 \mathrm{~K}$

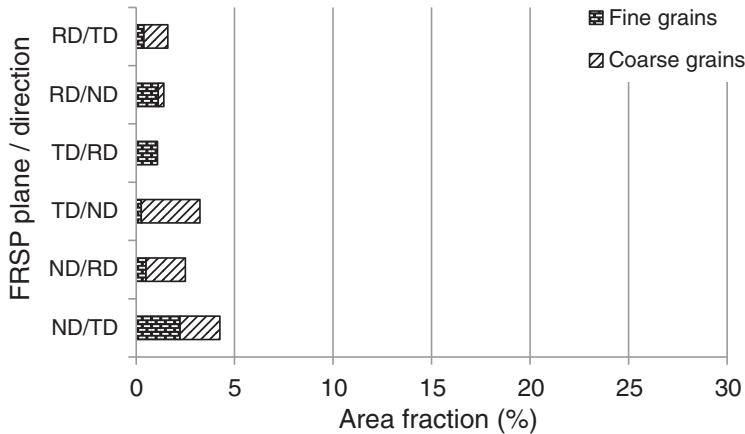

Fig. 13 Fractions of $\mathrm{F}\{111\}\langle 112\rangle$ orientation in fine- and coarse-grained layers of FRSPed specimens after annealing at $573 \mathrm{~K}, 623 \mathrm{~K}$ and $673 \mathrm{~K}$.

(a) As-received

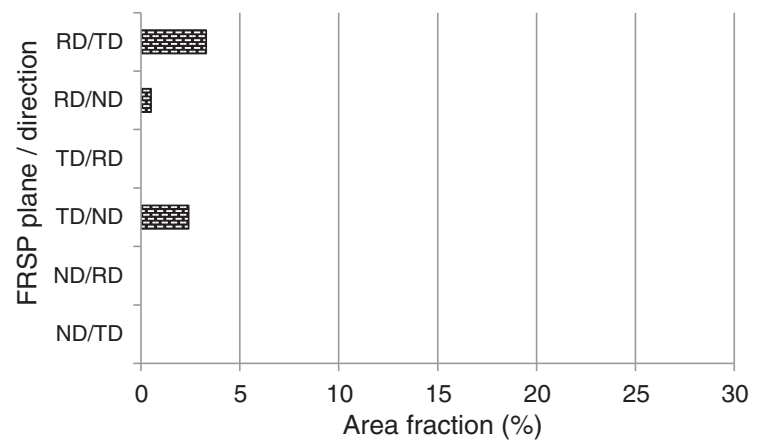

(c) Annealed at $623 \mathrm{~K}$

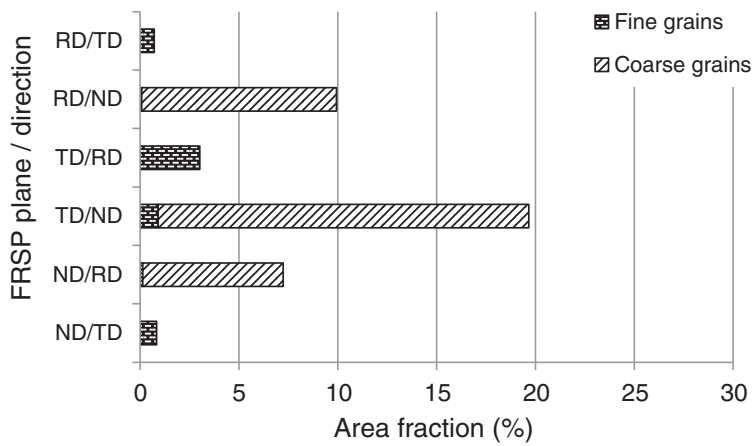

(b) Annealed at $573 \mathrm{~K}$

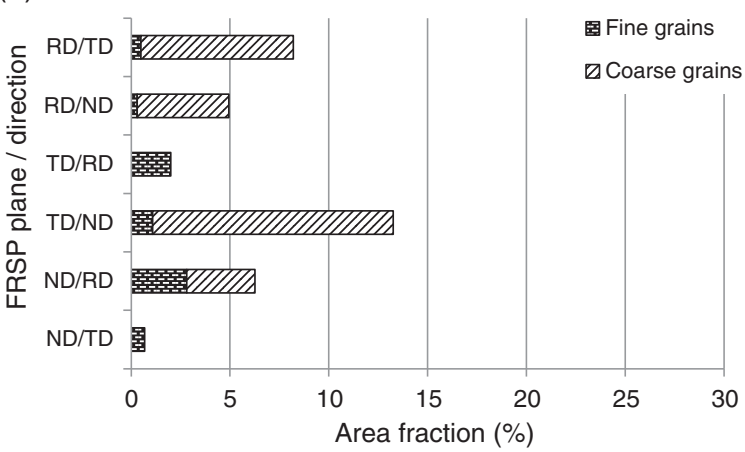

(d) Annealed at $673 \mathrm{~K}$

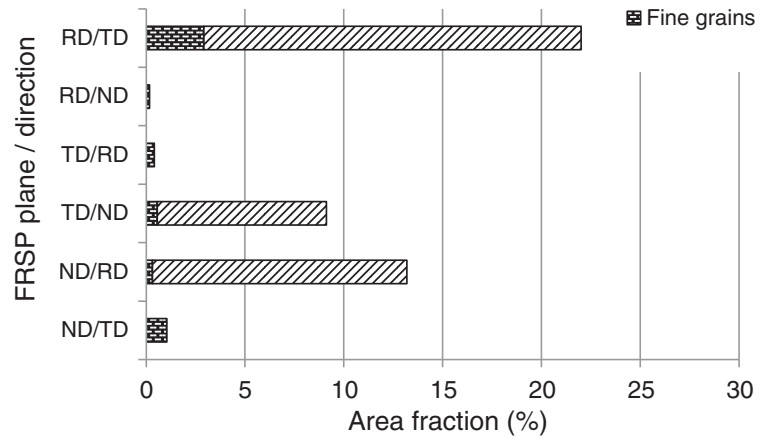

Fig. 14 Fractions of $\mathrm{E}\{111\}\langle 110\rangle$ orientation in fine- and coarse-grained layers of FRSPed specimens after annealing at $573 \mathrm{~K}$, $623 \mathrm{~K}$ and $673 \mathrm{~K}$.

$673 \mathrm{~K}$ annealing. In CG layer of TD/ND FRSPed specimens, the $\mathrm{E}$ fractions attained $12.2 \%, 18.7 \%$ and $8.6 \%$ at $573 \mathrm{~K}$, $623 \mathrm{~K}$ and $673 \mathrm{~K}$, respectively. On the other hand, little development of $\mathrm{E}$ orientation is observed for $\mathrm{TD} / \mathrm{RD}$ and ND/TD FRSPs. This fact strongly suggests existence of an orientation which $\mathrm{E}$ originates in.

\section{Discussion}

Formation of the shear texture by FRSP and subsequent annealing is discussed.

The as-received specimen had a cube texture (Fig. 4(a)), whereas it exhibited anisotropy in orientation for three 
specimen axes. Such anisotropy could be confirmed in the as-received ones of Figs. 8 and 11. The cube texture was converted to the shear texture by FRSP and annealing. Kim and Lee ${ }^{15)}$ reported the shear texture generated in asymmetric rolling depended on the shear to normal strain ratio, $\alpha$. As the absolute value of $\alpha$ increases, the stable orientation moves to a shear deformation texture and finally to the ideal shear deformation texture consisting of $\mathrm{H}\{001\}\langle 110\rangle$ and $\mathrm{F}$ $\{111\}\langle 112\rangle$ at $\alpha= \pm \infty$. After annealing the ideal shear texture changed into major $H$ and minor $\mathrm{ND} / /\langle 111\rangle$ components involving mainly $\mathrm{F}^{18)}$ In contrast, it should be noted that $\mathrm{E}$ orientation developed as the main component of the shear recrystallization texture in the FRSPed specimens (Fig. 14). Moreover, it should be emphasized that the E $\{111\}\langle 110\rangle$ orientation is a well-controllable shear texture component of fcc metals by processing because FRSP plane and direction are consistent with indices of slip planes and directions, respectively.

Textural evolution in the surface layer subjected to FRSP and subsequent annealing depended markedly on the processed plane and direction. This implies that an appropriate selection of FRSP plane and direction leads to formation of the sharper preferred orientation. As described above, little development of E orientation (Fig. 14) was observed for TD/RD and ND/TD FRSPs. On the other hand, the optimum combination of FRSP plane/direction was different in each annealing temperature. This is probably attributed to inhomogeneity of the analyzed microstructure with a relatively small area of about $160000 \mu \mathrm{m}^{2}$. The $\mathrm{E}\{111\}\langle 110\rangle$ orientation is included by both FRSP_nd $/ /\langle 111\rangle$ and FRSP_d $/ /\langle 110\rangle$ fiber textures, respectively. The total fraction of FRSP_nd $/ /\langle 111\rangle$ in FG and CG layers was small for RD/ND FRSP/A at $673 \mathrm{~K}$ and ND/TD FRSP/A at all of the three temperatures. The total fraction of FRSP_d// $/ 110\rangle$ in $\mathrm{FG}$ and $\mathrm{CG}$ layers was small for $\mathrm{RD} / \mathrm{ND} \mathrm{FRSP} / \mathrm{A}$ at $573 \mathrm{~K}$ and TD/RD FRSP/A at $673 \mathrm{~K}$ and ND/TD FRSP/A at the three temperatures. It follows from this discussion that ND/TD FRSP and annealing did not evolve E orientation which belongs to both fiber textures. Because Cube orientation, which was a main textural component of the as-received sample, was equivalent for the six kinds of FRSP conditions it seldom resulted in the formation of $\mathrm{E}$ orientation through FRSP and annealing. For RD/ND and TD/RD FRSPs, the formation of one of the two fiber textures was suppressed at an annealing temperature. This fact suggests that $\mathrm{E}$ orientation had less priority in nucleation among components of the fiber texture in the material subjected to $\mathrm{RD} / \mathrm{ND}$ and TD/RD FRSPs. The priority might be related to ease in recovery and amount of stored strain.

\section{Conclusions}

In the present study, FRSP and subsequent annealing have been applied to commercial purity aluminum so as to investigate texture evolution in specimens subjected to
FRSPs with six combinations of plane/direction. Further, the textural evolution was discussed in consideration of FRSP plane and direction. The obtained results are summarized as follows:

(1) The characteristic microstructure consisting of finegrained and coarse-grained layers in order from the processed surface are formed in the FRSPed and annealed specimens.

(2) The shear texture component $E\{111\}\langle 1 \overline{1} 0\rangle$, which is a well-controllable shear texture component of fcc metals by processing, mainly evolves in the specimen subjected to FRSP and annealing while Cube $\{001\}\langle 100\rangle$ orientation, the main component of the as-received specimen, declines. Fraction of E orientation evolved depends on FRSP plane and direction.

\section{Acknowledgments}

We wish to thank Research Division of texture, Japan Institute of Light Metals for providing the material and Mr. K. Itoh and Mr. S. Akaihata for their experimental collaborations. One of the authors (Y. T.) gratefully acknowledges the financial support by the Light Metal Educational Foundation inc., Japan.

\section{REFERENCES}

1) Y. Iwahashi, J. Wang, Z. Horita, M. Nemoto and T. G. Langdon: Scr. Mater. 35 (1996) 143-146.

2) Y. Saito, N. Tsuji, H. Utsunomiya, T. Sakai and R. G. Hong: Scr. Mater. 39 (1998) 1221-1227.

3) A. P. Zhilyaev, G. V. Nurislamova, B.-K. Kim, M. D. Baro, J. A. Szpunar and T. G. Langdon: Acta Mater. 51 (2003) 735-765.

4) S. C. Wang, M. J. Starink, N. Gao, X. G. Qiao, C. Xu and T. G. Langdon: Acta Mater. 56 (2008) 3800-3809.

5) Y. Fukuda, K. Oh-ishi, M. Furukawa, Z. Horita and T. G. Langdon: Acta Mater. 52 (2004) 1387-1395.

6) C. Lu, G. Y. Deng, A. K. Tieu, L. H. Su, H. T. Zhu and X. H. Liu: Acta Mater. 59 (2011) 3581-3592.

7) N. Kamikawa, N. Tsuji, X. Huang and N. Hansen: Acta Mater. 54 (2006) 3055-3066.

8) S. Li, F. Sun and H. Li: Acta Mater. 58 (2010) 1317-1331.

9) M. Shi, Y. Takayama, T. Umetsu, H. Kato, H. Watanabe and H. Inoue: Mater. Trans. 50 (2009) 210-214.

10) M. Shi, Y. Takayama, C. Ma, H. Watanabe and H. Inoue: Trans. Nonferrous Met. Soc. China 22 (2012) 2616-2627.

11) T. Sakai, S. Hamada and Y. Saito: Scr. Mater. 44 (2001) 25692573.

12) N. Kamikawa, T. Sakai and N. Tsuji: Acta Mater. 55 (2007) 58735888.

13) Y. Takayama, M. Shi, Y. Ougiya, K. Nonaka and H. Watanabe: Mater. Sci. Forum 702-703 (2012) 457-460.

14) T. Furu and E. Nes: Recrystallization'92, eds. by M. Fuentes and J. Gil Sevillano, (San Sebastian, Spain, 1992) p. 311.

15) K.-H. Kim and D. N. Lee: Acta Mater. 49 (2001) 2583-2595.

16) H. Jin and D. J. Lloyd: Mater. Sci. Eng. A 399 (2005) 358-367.

17) J. Sidor, A. Miroux, R. Petrov and L. Kestens: Acta Mater. 56 (2008) 2495-2507.

18) D. N. Lee and K.-H. Kim: Proc. Innovation in Processing and Manufacturing of Sheet Materials, ed. by M. Y. Demeri, (TMS, Warrendale, Penn., 2001) pp. 219-235. 